\title{
HER Catalytic Activity of Electrodeposited Ni-P Nanowires under the Influence of Magnetic Field
}

\author{
Hung-Bin Lee, ${ }^{1}$ Jiun-Chen Tsau, ${ }^{2}$ and Chun-Ying Lee ${ }^{3}$ \\ ${ }^{1}$ Department of Materials Science and Engineering, Da-Yeh University, Da-Tsuen, Changhua 515, Taiwan \\ ${ }^{2}$ Department of Electrical Engineering, Da-Yeh University, Da-Tsuen, Changhua 515, Taiwan \\ ${ }^{3}$ Department of Mechanical Engineering, National Taipei University of Technology, Taipei 106, Taiwan
}

Correspondence should be addressed to Chun-Ying Lee; leech@ntut.edu.tw

Received 23 November 2012; Accepted 26 June 2013

Academic Editor: Jie-Fang Zhu

Copyright (C) 2013 Hung-Bin Lee et al. This is an open access article distributed under the Creative Commons Attribution License, which permits unrestricted use, distribution, and reproduction in any medium, provided the original work is properly cited.

\begin{abstract}
Nickel alloy electrodes both in plane and nanowire morphologies were fabricated by electrodeposition in sulfamate bath. With the increasing concentration of phosphorous acid in the electrolyte, the $\mathrm{P}$ content in the deposition increased accordingly. In the meantime, the grain refined and even became amorphous in microstructure as the $\mathrm{P}$ content was raised. For the nanowire electrode, vibrating sample magnetometer (VSM) measurement showed that its coercivity was anisotropic and decreased with P-content. In addition, the easy axis for magnetization of the electrode was parallel to the axial direction of nanowire. The electrocatalytic activity measurement of the electrode in $0.5 \mathrm{M} \mathrm{H}_{2} \mathrm{SO}_{4}$ electrolyte showed that the nanowire electrode had higher activity than the plane one, and the alloying of $\mathrm{P}$ in Ni electrode raised its hydrogen evolution reaction (HER) performance. The enhanced performance of nanowire electrode was attributed to the smaller and more uniform hydrogen bubbles generated in HER reaction. Finally, the applied magnetic field (3.2 T) improved significantly the HER activity of Ni but not Ni-P electrode. By using nanowire morphology and applying magnetic field, the current density at $-0.75 \mathrm{~V}$ HER stability test of the Ni electrode increased fourfold more than its plane counterpart.
\end{abstract}

\section{Introduction}

Water electrolysis has been considered as one of the clean processes for producing hydrogen with less greenhouse effect, especially if the electricity is generated from renewable energy. Although the use of platinum electrode demonstrated the best electrocatalytic activity, the cost of this noble metal renders it difficult to be implemented for large scale production. Therefore, the research on the alternative electrode, which is more economic in industrial application, has been an important issue [1]. For water electrolysis, some of the control process parameters include type of electrolyte, electrode distance, temperature, and additives [2-4]. Nagai et al. reported the qualitative influences from the electrode space configuration, distance, and current density [2]. Other findings by Stojić and coworkers [3] and de Souza et al. [4] indicated that the ionic additive and shorter electrode distance improved the hydrogen evolution in $\mathrm{KOH}$ solution. The use of nickel-based electrode, including nickel, nickel alloy, rare earth doped nickel, and porous nickel, has apparently raised the electrocatalytic activity in water electrolysis [5]. Another frequently studied nickel-based electrode is Ni-P alloy. Several control factors, such as phosphorus content, surface area, internal stress, hydrogen adsorption energy, and electron configuration, were identified. In basic electrolyte, Burchardt [6] reported that the electrocatalytic activity reached maximum of $17 \%$ of $\mathrm{P}$ and increased with the coating thickness. Among three Ni-P coatings with $\mathrm{P}$ content of 7, 20, and 28\%, Królikowski and Wiecko [7] discovered that the crystalline Ni-7P in acidic electrolyte had better electrocatalytic property than its amorphous 20 and $28 \%$ counterparts. Shervedani and Lasia [8] proposed that the high electrocatalytic activity of amorphous Ni-P coating was indebted to its increase in surface area. A porous electrode surface was observed in the $\mathrm{NiP}_{8}$ coating which demonstrated the best electrocatalytic activity among $8 \%$ to $23 \%$ electrodes. Associated with the increase in internal stress, the coating sometimes developed cracking and 
raised the effective surface area. The electrocatalytic activity increased accordingly [9]. The increase in electrode surface area provided more space for hydrogen adsorption and, thereby, the electrocatalytic rate.

Nanomaterials, compared with its conventional bulk counterparts, possess relatively high specific surface area and surface atoms. These characteristics render them with superior electrocatalytic activity. For electrode materials in hydrogen evolution reactions, the enhancement in their activities by adopting nanomaterial fabricated from anodized aluminum oxide (AAO) has been frequently employed [1013]. More than four-time increase in the current density of $\mathrm{Ni}$ electrode with nanowire configuration over its plane counterpart was reported by Lee et al. [11]. Chen and coworkers [12] studied the electrocatalytic activity of $\mathrm{Ni}$ nanowire exposed from the AAO template with different lengths. In $1 \mathrm{M} \mathrm{Na}_{2} \mathrm{SO}_{4}$ electrolyte, they found that the current density increased with longer nanowires exposed from the template. In the meantime, in $0.5 \mathrm{M} \mathrm{H}_{2} \mathrm{SO}_{4}$ electrolyte Hsu et al. [13] found the similar trend with Ni-P nanowires. Usually, the electrodeposited Ni-P nanowires had better HER performance than $\mathrm{Ni}$ nanowires.

To further enhance the HER activity, the use of magnetic field has been proposed. Iida and coworkers [14] and Matsushima et al. [15] discussed the effect of externally imposed magnetic field during hydrogen evolution reaction. Studied with different electrode distances and electrolytes, they reported that high magnetic field, small electrode distance, and low electrolyte concentration could provide better HER activity. They attributed this enhancement to the electrolyte convection caused by magnetohydrodynamics (MHD). In the KOH electrolyte with $2 \mathrm{~mm}$ electrode distance and $4 \mathrm{~V}$ overpotential, Lin and coworkers reported that the performance of ferromagnetic Ni plane electrode was better than paramagnetic platinum and graphite electrodes [16].

In nanoscale, $\mathrm{Yu}$ and coworkers [17] prepared a single crystalline and superparamagnetic $\mathrm{Ni}$ nanowire electrode with 1110 Oe coercivity, much higher than polycrystalline $\mathrm{Ni}$ nanowire. For Ni-P nanowire with diameter of $200 \mathrm{~nm}$, Chiriac et al. [18] found the decrease in coercivity and increase in Curie temperature with phosphorus content. From the prior studies, it is understood that the HER catalytic activity is controlled by many parameters. Nevertheless, the considerations in practical application and cost should be emphasized. In this study, by combining the nanosized surface configuration of the electrode and the application of external magnetic field, both the increase in surface area and the enhancement of convection without additional constant input of energy should benefit the HER activity in water electrolysis. Therefore, the electrocatalytic activity of the electrodeposited Ni-P nanowires under the influence of magnetic field was investigated.

\section{Experimental}

With the same electroplating parameters, both plane and nanowire electrodes were fabricated in this study first. Subsequently, the electrochemical property and microstructure and surface morphology of the electrode were measured
TABLE 1: Plating parameters used in this study.

\begin{tabular}{lc}
\hline Parameter & Magnitude \\
\hline $\mathrm{N}^{2+}$ & $90 \mathrm{~g} / \mathrm{L}$ \\
$\mathrm{NiCl}_{2}$ & $3 \mathrm{~g} / \mathrm{L}$ \\
$\mathrm{H}_{3} \mathrm{BO}_{3}$ & $40 \mathrm{~g} / \mathrm{L}$ \\
$\mathrm{H}_{3} \mathrm{PO}_{3}$ & $0,10,20,30,40 \mathrm{~g} / \mathrm{L}$ \\
Wetting agent & $1 \mathrm{~mL} / \mathrm{L}$ \\
Current mode & Square pulse $500 \mathrm{~Hz}$ \\
Current density & $8 \mathrm{~A} / \mathrm{dm}^{2}$ \\
Bath temperature & $50^{\circ} \mathrm{C}$ \\
\hline
\end{tabular}

and examined. Field emission scanning electron microscope ((FESEM) JEOL 6700, Japan), X-ray diffractometer ((XRD) SHIMADZU XRD-6000, Japan), and high resolution transmission electron microscope ((HRTEM) JEOL JEM2100F, Japan) were used for the structural examinations. The application of magnetic field with permanent magnet during HER activity measurement was employed to investigate its effect. In addition, the magnetic property of the electrode was tested using vibrating sample magnetometer ((VSM) Lake Shore 7407, USA).

2.1. Plane Electrode. The substrate used for the electroplating was $0.3 \mathrm{~mm}$ thick phosphor deoxidized copper plate (C1220P). Nickel pallets (S-rounds) with $25 \mathrm{~mm}$ diameter and $6 \mathrm{~mm}$ thickness were employed as anode. The substrate was cut into $1.5 \times 1.5 \mathrm{~cm}^{2}$ and heat-treated at $200^{\circ} \mathrm{C}$ for one hour to remove the residual stress. Before electroplating, the substrate was polished with emery papers (no. 240 \#1200), activated in $5 \%$ sulfuric acid solution, and rinsed with de-ionized water.

2.2. Anodized Aluminum Oxide (AAO) Template. The high purity aluminum foil $(99.999 \%)$ was first annealed at $500^{\circ} \mathrm{C}$ in nitrogen atmosphere for 3 hours. The annealed aluminum foil was then ultrasonically cleaned for $5 \mathrm{~min}$ and wiped clean with alcohol. Inside an electrolyte with sulfuric acid, phosphoric acid, and deionized water in $40 \mathrm{wt} \%$ : $40 \mathrm{wt} \%: 20 \mathrm{wt} \%$ concentration, the aluminum foil was subsequently electropolished with $20 \mathrm{~V}$ voltage for $10 \mathrm{~min}$. Following the rinse with de-ionized water, an anodizing treatment in $0.5 \mathrm{M}$ oxalic acid solution at $4^{\circ} \mathrm{C}$ was performed. A DC power supply provided a $60 \mathrm{~V}$ voltage between the aluminum specimen and graphite electrodes for 3 hours. The thus formed aluminum oxide film was removed with $5 \mathrm{wt} \% \mathrm{NaOH}$ solution. The specimen was then subjected to a second anodizing treatment for 4 hours. Since the oxidation was not yet complete through the thickness of the specimen, the residual aluminum substrate was dissolved away with $0.1 \mathrm{M} \mathrm{CuCl} \cdot \mathrm{HCl}$ solution. After removing the barrier layer with $6 \mathrm{wt} \%$ phosphoric acid, the AAO template was obtained. However, for conducting current in later electrodeposition, a thin Au film was sputtered on one side of the template.

2.3. Electrodeposition of Ni Alloys in AAO Template. For the electrodeposition of $\mathrm{Ni}$ alloys in AAO template, a platinum plate was used as the anode. A square pulse with 


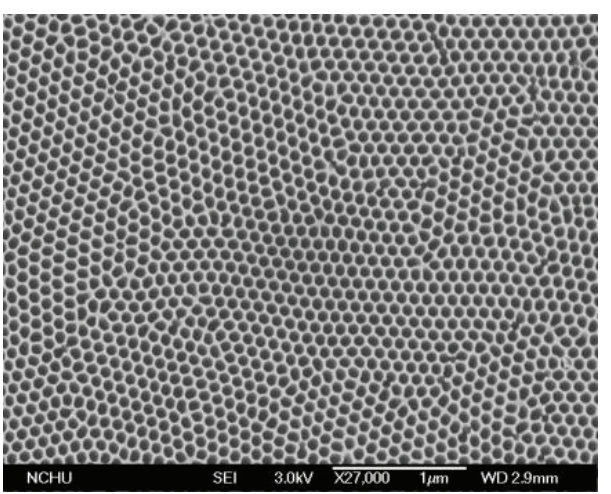

(a)

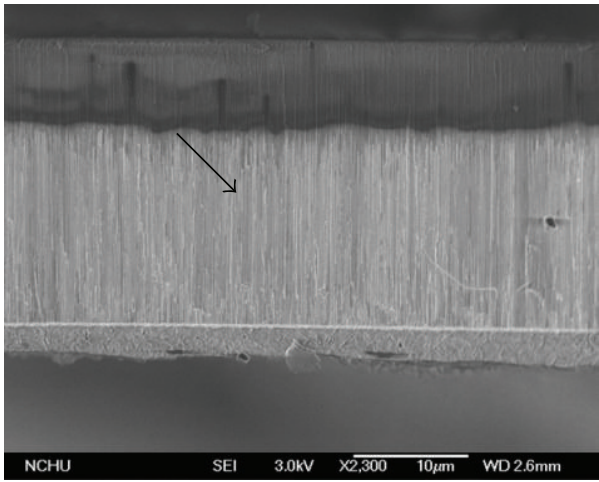

(c)

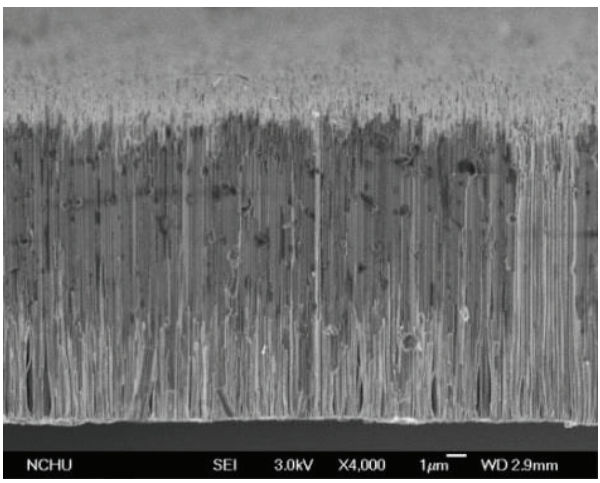

(e)

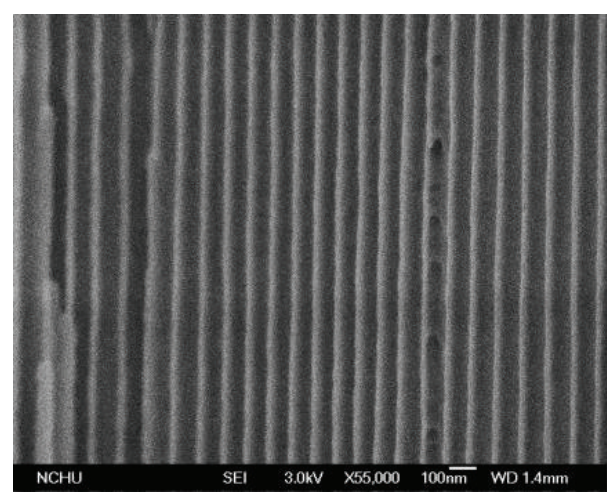

(b)

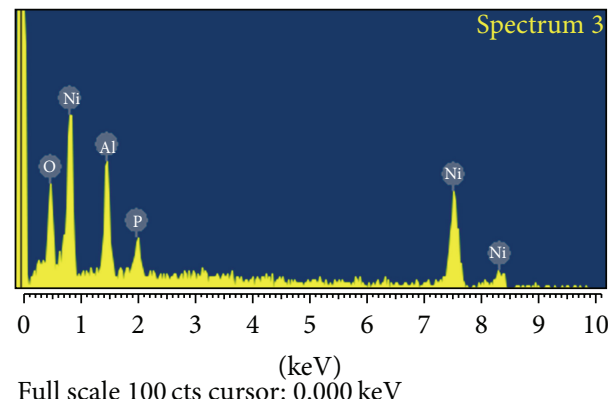

(d)

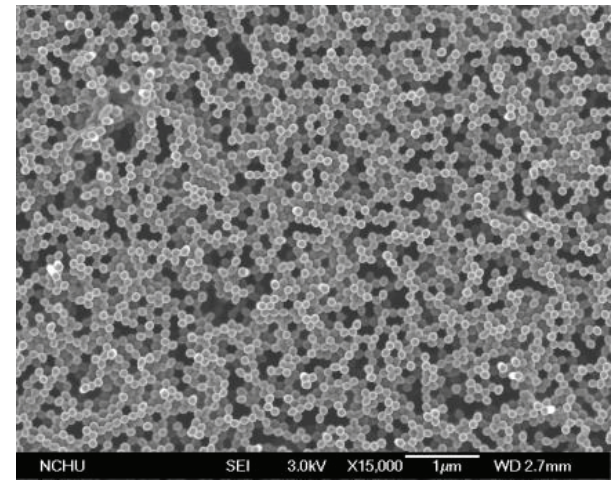

(f)

FIGURE 1: The microscopic examinations using field emission scanning electron microscope: (a) plane view of the AAO template, (b) longitudinal section of the AAO template, (c) longitudinal section of the nickel alloy nanopattern electrode, (d) EDS spectrum of nano pattern electrode, (e) longitudinal section of the nickel alloy nanowire electrode, and (f) plane view of the nickel alloy nanowire electrode.

peak current density of $8 \mathrm{~A} / \mathrm{dm}^{2}$ and frequency of $500 \mathrm{~Hz}$ was generated from a precision function generator (WAVE FACTORY WF1943, NF, Japan) and amplified through a power amplifier (NF TA-250, Japan). The nickel sulfamate electrolytes consisting of $90 \mathrm{~g} / \mathrm{L}$ nickel ion, $40 \mathrm{~g} / \mathrm{L}$ boric acid, $3 \mathrm{~g} / \mathrm{L}$ nickel chloride, $1 \mathrm{ml} / \mathrm{L}$ wetting agent, and various (0 40 g/L) phosphorous acid concentrations for preparing different electrodes were employed, as listed in Table 1.

2.4. Electrochemical Measurement. A potentiostat (EG\&G 263A, Princeton Applied Research, USA) and a threeelectrode container were used in the electrochemical measurement in this study. The prepared plane specimen or nanopatterned specimen was employed as the working electrode with $1 \mathrm{~cm}^{2}$ exposed area in the $0.5 \mathrm{M} \mathrm{H}_{2} \mathrm{SO}_{4}$ electrolyte. A platinum wire with $0.5 \mathrm{~mm}$ in diameter and $25 \mathrm{~cm}$ in length and a saturated calomel electrode (SCE) served as the counter electrode and reference electrode, respectively. The specimen was first trimmed into $2.0 \mathrm{~cm}$ square and then rinsed fully with de-ionized water. The following electrochemical measurements were performed: (1) cathodic polarization curve scanned from $0 \mathrm{~V}$ to $-0.9 \mathrm{~V}$ with scan rate of $1 \mathrm{mV} / \mathrm{s}$; (2) HER stability measurement conducted at fixed voltage of $-0.75 \mathrm{~V}$ versus SCE for 6 hours. 
TABLE 2: The P content of nanowires deposited from the bath with different $\mathrm{H}_{3} \mathrm{BO}_{3}$ concentrations.

\begin{tabular}{lccccc}
\hline $\begin{array}{l}\mathrm{H}_{3} \mathrm{BO}_{3} \\
\text { concentration }\end{array}$ & $0 \mathrm{~g} / \mathrm{L}$ & $10 \mathrm{~g} / \mathrm{L}$ & $20 \mathrm{~g} / \mathrm{L}$ & $30 \mathrm{~g} / \mathrm{L}$ & $40 \mathrm{~g} / \mathrm{L}$ \\
\hline $\mathrm{P}$ content (at\%) & $0 \%$ & $9.76 \%$ & $12.53 \%$ & $15.44 \%$ & $23.29 \%$ \\
\hline
\end{tabular}

\section{Results}

3.1. Morphology of AAO Template and the Fabricated Nanoelectrodes. The AAO template prepared from the aforementioned process is shown in Figure 1. It is seen that the holes were in parallel arrangement through the template thickness with $75 \mathrm{~nm}$ diameter, $115 \mathrm{~nm}$ pitch, $25 \mu \mathrm{m}$ thickness, and $7.9 \times$ $10^{9} / \mathrm{cm}^{2}$ areal density. Figure 1 (c) reveals that the nanowires grew inside the nanopores from the bottom of the AAO template. The nominal dimensions of the nanowires were $75 \mathrm{~nm}$ in diameter and $15 \mu \mathrm{m}$ in length, which corresponded to the approximate aspect ratio of 200. This prepared specimen was called $\mathrm{Ni}-\mathrm{P}\left(\mathrm{Ni}_{100-x}-\mathrm{P}_{x}\right)$ alloy nanopattern electrode. The associated compositions measured from energy dispersive spectrometer (EDS) indicated four constituents- $\mathrm{O}, \mathrm{Al}, \mathrm{Ni}$, and $\mathrm{P}$, as presented in Figure $1(\mathrm{~d})$. Disregarding the signals of $\mathrm{Al}$ and $\mathrm{O}$, the $\mathrm{P}$ contents of the nanowires are presented in Table 2. The results show that the $\mathrm{P}$ content increased with the concentration of phosphorous acid used in the electrolyte. By submersing the nano pattern electrode in $5 \mathrm{wt} \% \mathrm{NaOH}$ solution for sufficient duration, the AAO template was dissolved, and the nanowires were exposed. Finally, a Ni-P nanowire electrode was obtained, as presented in Figures 1(e) and $1(\mathrm{f})$.

3.2. Structural Examination on the Nanowires. The X-ray diffraction patterns of nickel alloy nanowires prepared in electrolyte with different phosphorous acid contents are shown in Figure 2. The broadening of the diffraction peaks for the electrode with increasing phosphorous acid content indicated that the grain was refined. Moreover, for the pure $\mathrm{Ni}$ coating the ratio between the (200) and (111) peak intensities was higher than that of powder nickel. This denoted that the prepared pure nickel coating at $8 \mathrm{~A} / \mathrm{dm}^{2}$ current density in this sulfamate bath had preferred (200) texture. However, it is apparently shown in Figure 2 that with the presence of phosphorous acid in the electrolyte the deposited coatings had nearly no (200) diffraction peak and changed their texture to (111). When the phosphorous acid content reached $40 \mathrm{~g} / \mathrm{L}$, almost no diffraction peak was detected, as shown in Figure 2(e), and the electrode became amorphous. According to the full width at half maximum of (111) diffraction peak and Scherrer formula [19], the calculated grain sizes of the electrodes were presented in Figure 3. Also shown in Figure 3 are the associated $\mathrm{P}$ contents in the electrodes. The results showed that the grain size decreased while the $\mathrm{P}$ content of the electrode increased with the addition of $\mathrm{H}_{3} \mathrm{PO}_{3}$ in the electrolyte.

The specimen for TEM examination was cut with ultramicrotome (Reichert-Jung Ultracut E, Austria) in $1 \mathrm{~mm} / \mathrm{s}$ and thickness $700 \AA$, placed in copper grid, and air-dried.

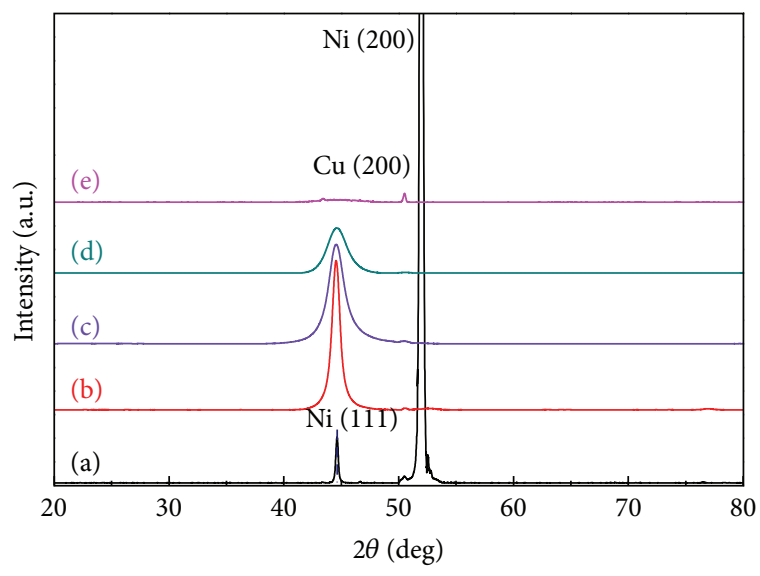

FIGURE 2: X-ray diffraction patterns of nickel alloy nanowires prepared in electrolyte with different phosphorous acid contents: (a) 0, (b) 10, (c) 20, (d) 30, and (e) $40 \mathrm{~g} / \mathrm{L}$.

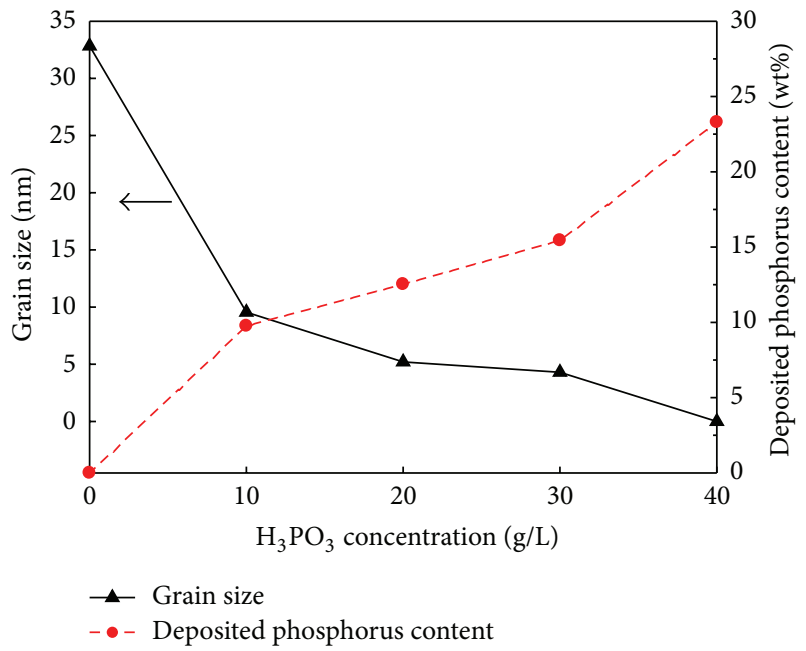

FIgURE 3: The influence of the $\mathrm{H}_{3} \mathrm{PO}_{3}$ concentration in the electrolyte on the grain size and deposited $\mathrm{P}$ content of the prepared electrode.

Figure 4(a) shows that electrodeposited nanowires adhered closely to the gold substrate. The line scan of the composition in Figure 4(b) revealed the traces of $\mathrm{Au}, \mathrm{O}, \mathrm{Al}$, and $\mathrm{Ni}$, which were the signals from substrate, AAO template, and nanowire, respectively. The TEM examination was also taken on the Ni-P nanowires embedded in the AAO template and was presented in Figure 4(c). The inset of this figure shows the selected area diffraction (SAED) pattern of the $\mathrm{Ni}-\mathrm{P}$ nanowire. Apparently, the nanowire was amorphous in nature.

3.3. Magnetic Measurement on the Ni-P Nanowires. The magnetic characteristics of the prepared electrodes were measured by using a vibrating sample magnetometer (VSM). The specimen dimensions were $0.3 \mathrm{~cm} \times 0.3 \mathrm{~cm} \times 20 \mu \mathrm{m}$, and the temperature was at room temperature $(300 \mathrm{~K})$. To avoid the connection between nanowires due to overplating 


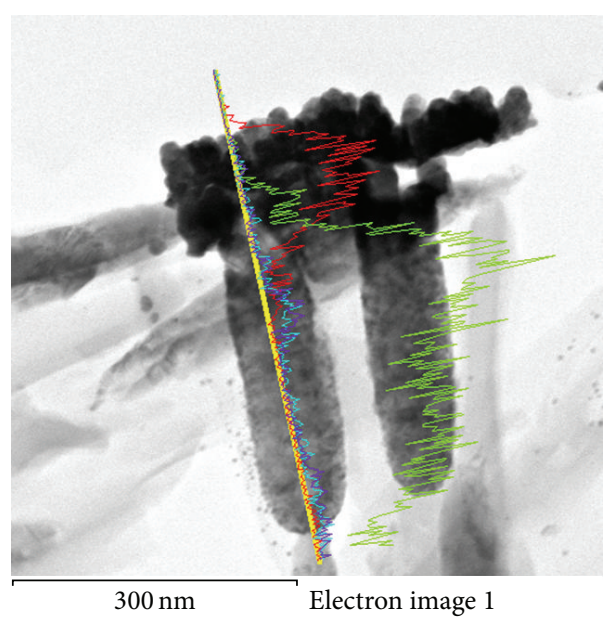

(a)

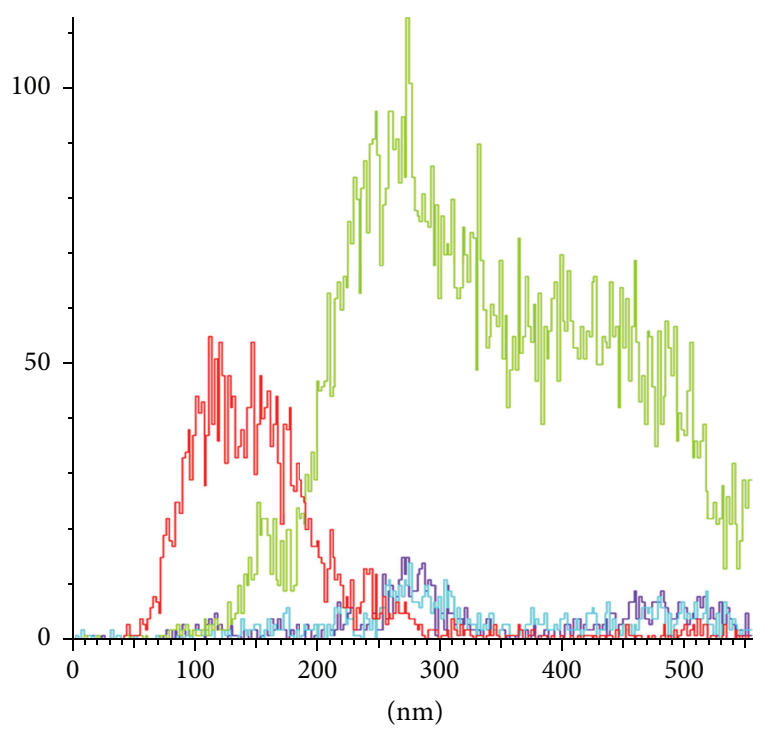

Aluminum Ka1, oxygen Ka1, nickel Kaland gold La1

(b)

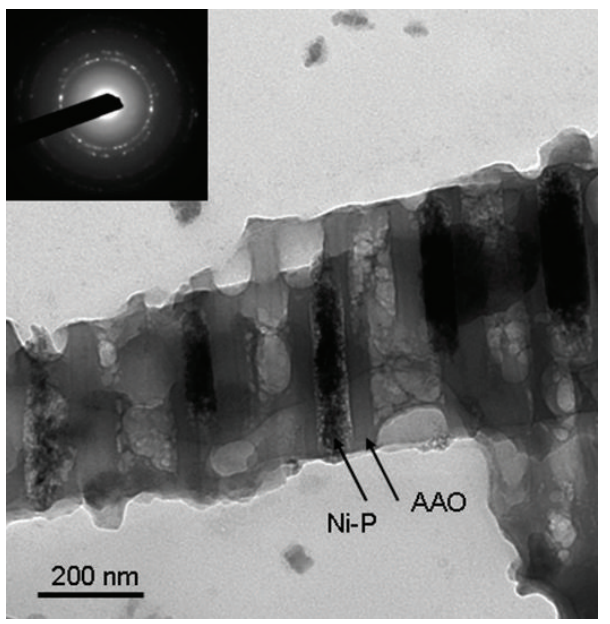

(c)

FIGURE 4: TEM micrographs of (a) Ni nanowires and (b) composition line scan in (a), (c) Ni-P nanowires in AAO template.

above the AAO template, the filled-in length of the nanowires was controlled to $15 \mu \mathrm{m}$ nominally, as shown in Figure 2(c). For these nanopattern electrodes, the measurements were performed in $\mathrm{H}_{\perp}$ and $\mathrm{H}_{/ /}$directions, where $\mathrm{H}_{\perp}$ and $\mathrm{H}_{/ /}$ denoted the directions of magnetic field in perpendicular and parallel to the plane of AAO template, respectively. In other words, $\mathrm{H}_{\perp}$ and $\mathrm{H}_{/ /}$were in parallel and perpendicular directions with the longitudinal axis of the nanowires, respectively. Figure 5 presents the measured hysteresis loops in $\mathrm{H}_{\perp}$ direction of the $\mathrm{Ni}_{100-x} \mathrm{P}_{x}$ electrodes. It is clearly seen that the hysteresis loop almost diminished and the coercivity decreased drastically with the increase of P-content in the nanowires. The nanowire with 23.29 at \% P showed nearly no coercivity, and the amorphous nature of this Ni$\mathrm{P}$ nanowire should be the main cause for this result. Similar measurements were also conducted in the $\mathrm{H}_{/ /}$direction, and the results are listed in Table 3 . Because of the dimensional anisotropy, the measured coercivities for pure $\mathrm{Ni}$ electrode in $\mathrm{H}_{\perp}$ and $\mathrm{H}_{/ /}$were $684.9 \mathrm{Oe}$ and $117.9 \mathrm{Oe}$, respectively. Furthermore, the associated squarenesses were 0.866 and 0.068 . These results revealed that the easy axis for magnetization of the electrode was parallel to the axial direction of nanowire [17]. Again, the coercivity decreased in both directions as the $\mathrm{P}$ content in the nanowires increased.

3.4. The Influence of Magnetic Field on the Electrocatalytic Activity. Three different morphologies of the electrodes were employed in the cathodic polarization measurements: plane, nanopattern, and nanowire. Figure 6(a) presents the polarization curves of the electrodes without the application of magnetic field. Considering the portion of the polarization curve at low potential $(<0.75 \mathrm{~V})$, the Ni-P electrode had higher current density, that is, higher electrocatalytic activity, than its Ni counterparts with corresponding electrode morphology. 


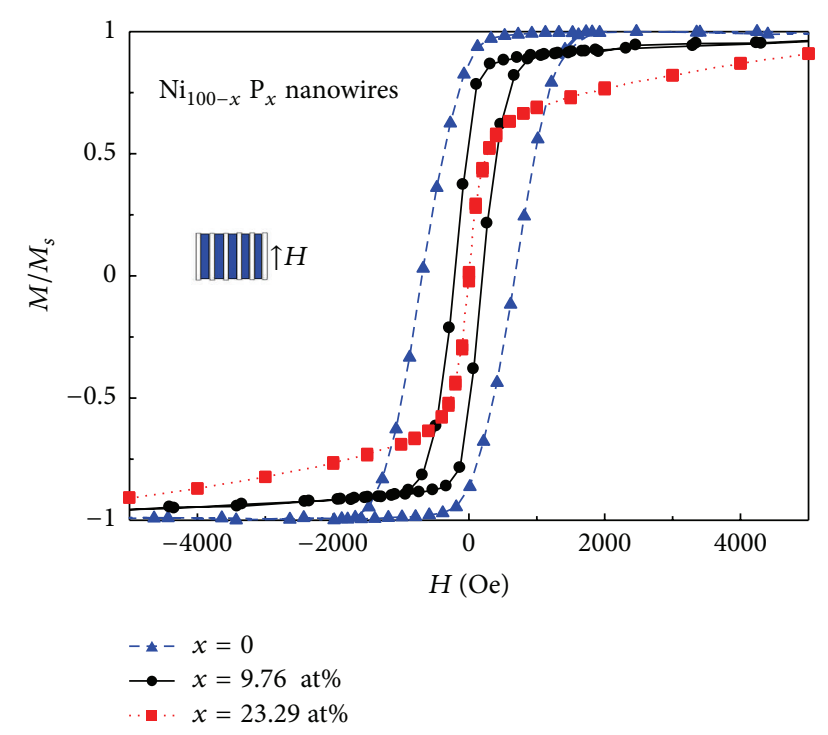

FIgURE 5: Hysteresis loops in $\mathrm{H}_{\perp}$ direction for $\mathrm{Ni}$-P nanowires with different $\mathrm{P}$ contents.

Moreover, for both $\mathrm{Ni}$ and Ni-P electrodes the electrocatalytic activity of the electrode decreased in the following order: nanowire, nano pattern, and plane. These results should be attributed to the higher specific surface area of nanowire electrode and the more active catalytic property of the Ni-P alloy $[8,13]$.

Figure 6(b) presents the polarization curves of the electrodes measured under the applied magnetic field of $3.2 \mathrm{~T}$. It can be seen that, although the current densities of the $\mathrm{Ni}$ nano pattern and nanowires were lower than their Ni-P counterparts at low potentials, they surpassed the latters at high potentials. The stronger coercivity of the Ni nanoelectrodes, as presented in Table 3 , should induce higher magnetic field near the electrode. The enhanced local magnetic field could interact with the electrolyte and promote the magnetohydrodynamic motion. In this study, the direction of the applied magnetic field was set to generate Lorentz force which acted in the same direction with buoyancy. Thus, the Lorentz force facilitated the escape of hydrogen bubbles from the cathode surface and assisted the HER reaction. Consequently, the electrocatalytic activity increased under the influence of applied magnetic field accordingly [16].

\section{Discussion}

4.1. The Effect of Electrode Morphology on HER Activity. The better electrocatalytic performance of Ni-P alloy over its pure Ni counterpart was confirmed from the measurements presented in Figure 6(a). The electron transfer in Ni alloying with $\mathrm{P}[13,20]$ and the change in crystalline texture of Ni$\mathrm{P}$ with $\mathrm{P}$ content $[21,22]$ have been associated with the enhancement of this catalytic property. The grain refinement and even amorphism for the prepared Ni-P nanowires were confirmed through the XRD and TEM examinations shown in Figures 2-4. Moreover, the increase in specific surface area of the electrode by exposing longer nanowires contributes to
TABLE 3: Coercivity and squareness of Ni-P nanowires.

\begin{tabular}{lccc}
\hline $\begin{array}{l}\text { Nanowires } \\
\mathrm{Ni}_{100-x} \mathrm{P}_{x} \text { (at \%) }\end{array}$ & $\begin{array}{c}\text { Magnetization } \\
\text { axis }\end{array}$ & $\begin{array}{c}\text { Coercivity } \\
\mathrm{Hc}(\mathrm{Oe})\end{array}$ & $\begin{array}{c}\text { Squareness } \\
\left(M_{r} / M_{s}\right)\end{array}$ \\
\hline \multirow{2}{*}{$x=0$} & $\mathrm{H}_{\perp}$ & 684.85 & 0.866 \\
& $\mathrm{H}_{/ /}$ & 117.86 & 0.068 \\
$x=9.76$ & $\mathrm{H}_{\perp}$ & 45.11 & 0.078 \\
& $\mathrm{H}_{/ /}$ & 4.36 & 0.0018 \\
$x=23.39$ & $\mathrm{H}_{\perp}$ & 7.05 & 0.0085 \\
& $\mathrm{H}_{/ /}$ & 2.63 & 0.0007 \\
\hline
\end{tabular}

the improved HER activity [12]. However, based on solely the comparison the electrode surface area is not consistent with the results presented in Figure 6(a). The nano pattern electrode consists nominally of arrays of separated $\mathrm{Ni}$ area in $75 \mathrm{~nm}$ diameter, $115 \mathrm{~nm}$ pitch, and $7.9 \times 10^{9} / \mathrm{cm}^{2}$ areal density. The thus calculated electrode surface area is only $36 \%$ of its plane counterpart. But the result in Figure 6(a) shows that the nanopattern electrode had better electrocatalytic property than the plane one. The mechanisms for this HER enhancement can be as follows.

It has been reported that the electric field concentration near the perimeter of the nanopatterned configuration can alter the overall current efficiency and raise HER activity of the electrode $[13,23]$. In addition, a detailed examination on the evolution of hydrogen bubbles near the electrode at $-0.75 \mathrm{~V}$ was performed with plane electrode and nanopattern electrode, respectively. Figure 7(a) shows the picture taken by a high speed CCD camera on the plane electrode. It was found that the bubbles of various sizes were elevated from the electrode surface. On the other hand, the bubbles generated from the nano pattern electrode were smaller in size and more uniform in size distribution, as shown in Figure 7(b). The smaller bubble should stay adjacent to the electrode surface in shorter duration, because it has less time to grow before escape from the electrode. The larger bubble takes more time to grow and blocks the electrode surface for longer duration. Therefore, with larger hydrogen bubbles over its surface, the plane electrode is not as active as the nano pattern electrode.

4.2. The Effect of Magnetic Field on HER Activity. As mentioned previously and shown in Figure 6(b), under the influence of applied magnetic field the paramagnetic $\mathrm{Ni}$ electrode enhanced its electrocatalytic activity. The stability of the electrodes in longer duration of HER reaction was further investigated. Figure 8 presents the monitored current density within 6-hour duration for electrode at constant $-0.75 \mathrm{~V}$ potential in $0.5 \mathrm{M} \mathrm{H}_{2} \mathrm{SO}_{4}$ electrolyte. For plane electrode both with and without the applied magnetic field, the current density first decreased and then recovered gradually. However, under the influence of magnetic field, the electrode recovered its current density faster than under no magnetic field. After the initial stage, the applied magnetic field steadily enhanced the HER activity of the plane electrode. For the nanowire electrode, the effect of magnetic field was even more prominent. The measured current density was nearly double its magnitude with the application of magnetic field. 


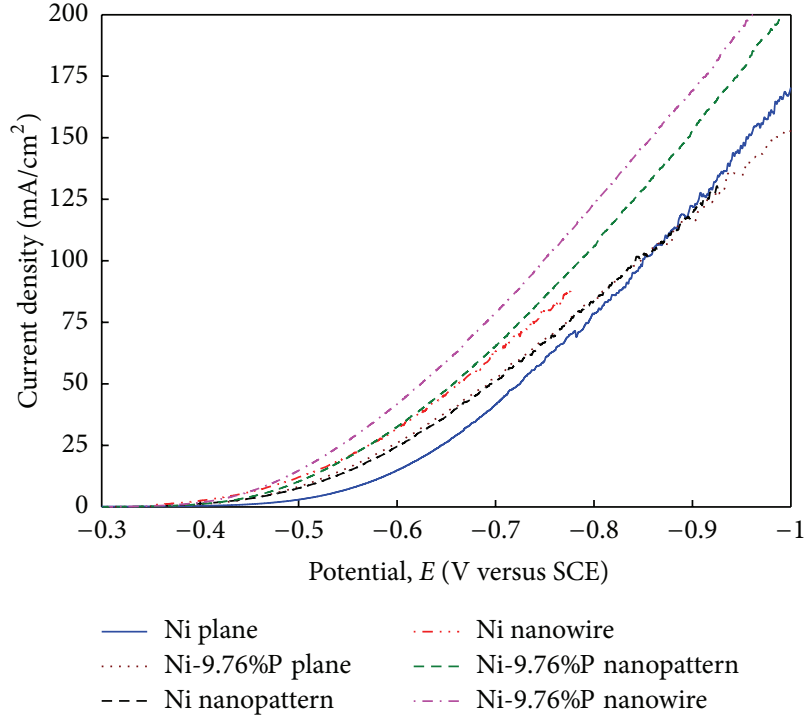

(a)

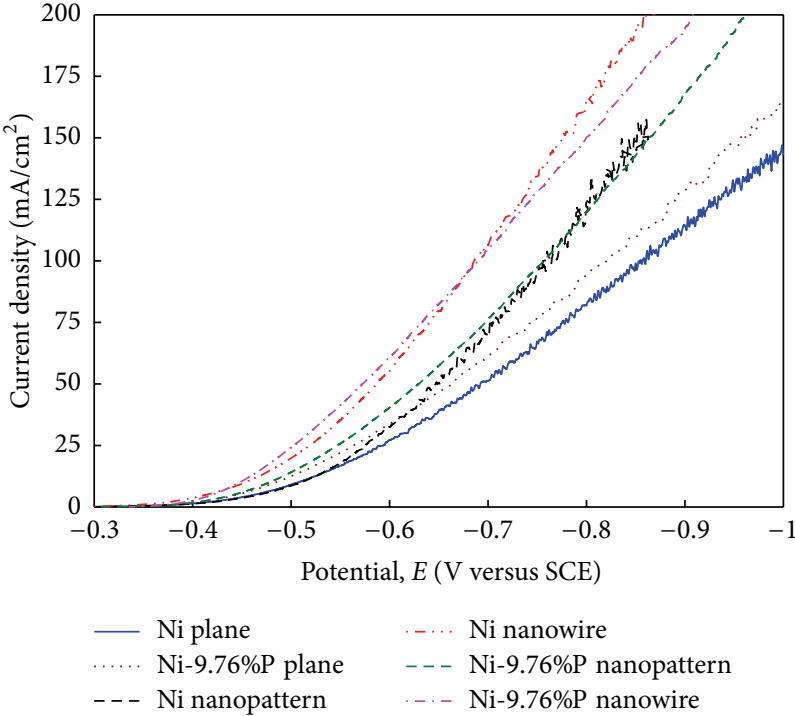

(b)

FIgURE 6: Cathodic polarization curves of Ni electrodes (a) without applied magnetic field, (b) with applied magnetic field of $3.2 \mathrm{~T}$.

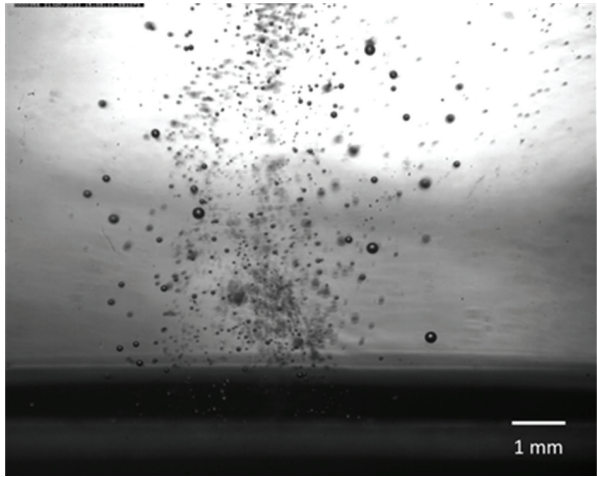

(a)

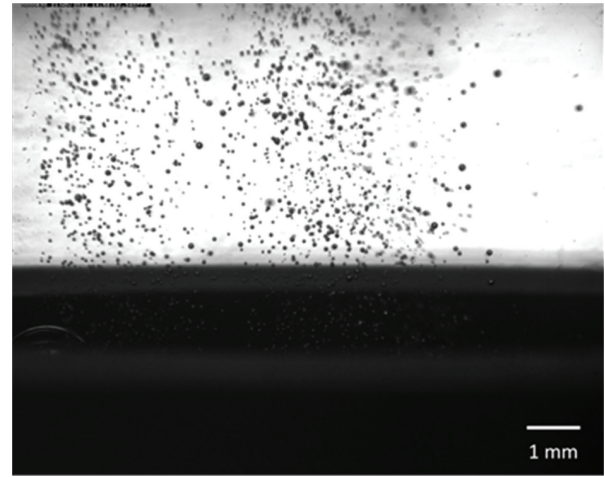

(b)

Figure 7: The evolution of the hydrogen bubbles over the electrode surface at constant $-0.75 \mathrm{~V}$ potential: (a) plane electrode, (b) nanopattern electrode.

Nevertheless, the slope of $i$ - $t$ curves gradually decreased over time. Shown in Figure 9 are the FESEM micrographs of the specimens after this 6-hour stability test. It is obviously seen in Figure 9(a) that the remained length of the nanowires was $6 \mu \mathrm{m}$, much shorter from its pristine length of $15 \mu \mathrm{m}$. The top ends of the nanowires were broken which might be caused by its oxidation in acidic solution and became brittle in nature [13]. Figure 9(b) shows the aggregation of nanowires at their top ends after being dried out for SEM examination. Whether this aggregation persists when the electrode is submerged in the electrolyte is uncertain. Therefore, its effect on the HER activity is unclear. Despite this deterioration in electrode, the overall current density increased by fourfold with the introduction of nanowire morphology and magnetic field. Therefore, how to alleviate the electrode damage and prolong the electrode life should be topics for further study.

\section{Summary}

Different designs in electrode morphology by employing AAO template and the electrodeposition of Ni-P alloy were investigated herein along with the effect of applied magnetic field during HER reaction. The increased concentration of phosphorous acid in electrolyte during electrodeposition raised the $\mathrm{P}$ content and refined the grain size of the electrode. The electrocatalytic activity of the electrode was thus enhanced by the incorporation of $\mathrm{P}$ in the $\mathrm{Ni}$ substrate. Although the nanopattern electrode had less exposed electrode surface area than its plane counterpart during HER measurement, the smaller and more uniform bubbles generated by the evenly distributed reaction sites helped their quick escape from the electrode surface. Therefore, it could maintain highly active electrode surface without the blockade 


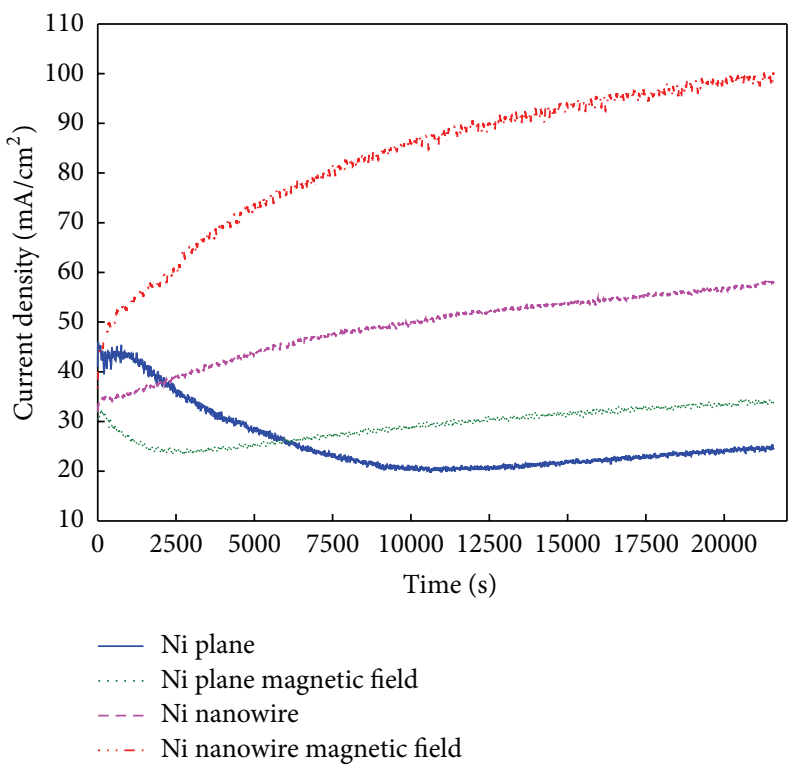

FIGURE 8: The measured $i$ - $t$ curves of Ni electrodes at constant $-0.75 \mathrm{~V}$ potential.

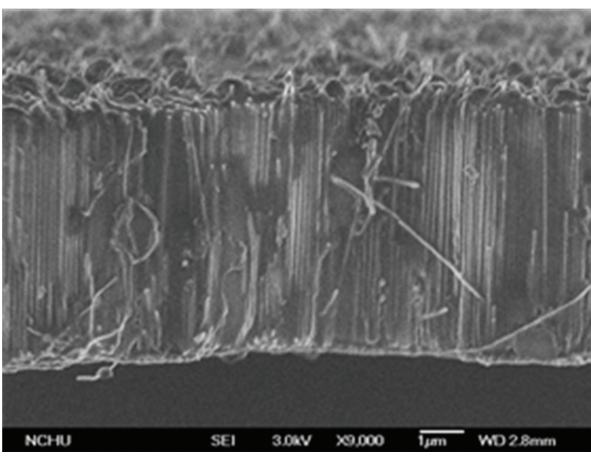

(a)

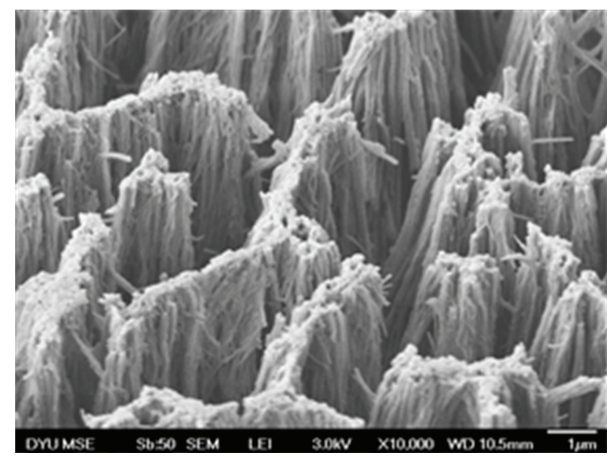

(b)

FIGURE 9: The FESEM micrographs of nanowire electrode after 6 hours of HER stability test at $-0.75 \mathrm{~V}$ : (a) cross-sectional view, (b) top view.

of nonconducting bubbles adjacent to the electrode and show higher HER activity than the plane electrode. On the other hand, the $\mathrm{P}$ content decreased the coercivity of Ni-P alloy. The beneficial effect of applying magnetic field during HER reaction to increase the electrocatalytic activity was not as significant as the Ni electrode. With the use of nanowire $\mathrm{Ni}$ electrode and under the assistance of magnetic field, the current density of the HER reaction could be increased by fourfold over its plane electrode counterpart. Nevertheless, the damage of the nanowires over longer duration of HER reaction deteriorated the performance of the electrode. The prevention of this electrode deterioration needs further study.

\section{Acknowledgment}

The financial support provided by the National Science Council, Taiwan, under Grant no. NSC-98-2221-E-027-083MY3 is gratefully acknowledged.

\section{References}

[1] M. M. Jakšić, "Advances in electrocatalysis for hydrogen evolution in the light of the Brewer-Engel valence-bond theory," International Journal of Hydrogen Energy, vol. 12, no. 11, pp. 727752, 1987.

[2] N. Nagai, M. Takeuchi, T. Kimura, and T. Oka, "Existence of optimum space between electrodes on hydrogen production by water electrolysis," International Journal of Hydrogen Energy, vol. 28, no. 1, pp. 35-41, 2003.

[3] D. L. Stojić, M. P. Marčeta, S. P. Sovilj, and Š. S. Miljanić, "Hydrogen generation from water electrolysis-possibilities of energy saving," Journal of Power Sources, vol. 118, no. 1-2, pp. 315319, 2003.

[4] R. F. de Souza, J. C. Padilha, R. S. Gonçalves, M. O. de Souza, and J. Rault-Berthelot, "Electrochemical hydrogen production from water electrolysis using ionic liquid as electrolytes: towards the best device," Journal of Power Sources, vol. 164, no. 2, pp. 792798, 2007. 
[5] G. Lu, P. Evans, and G. Zangari, "Electrocatalytic properties of Ni-based alloys toward hydrogen evolution reaction in acid media," Journal of the Electrochemical Society, vol. 150, no. 5, pp. A551-A557, 2003.

[6] T. Burchardt, "Hydrogen evolution reaction on NiPx alloys," International Journal of Hydrogen Energy, vol. 25, no. 7, pp. 627634, 2000.

[7] A. Królikowski and A. Wiecko, "Impedance studies of hydrogen evolution on Ni-P alloys," Electrochimica Acta, vol. 47, no. 13-14, pp. 2065-2069, 2002.

[8] R. K. Shervedani and A. Lasia, "Studies of the hydrogen evolution reaction on Ni-P electrodes," Journal of the Electrochemical Society, vol. 144, no. 2, pp. 511-519, 1997.

[9] H.-B. Lee, C.-H. Hsu, and D.-S. Wu, "A study on the hydrogen evolving activity of electroplated Ni-P coating by using the taguchi method," Journal of New Materials for Electrochemical Systems, vol. 14, no. 4, pp. 237-245, 2011.

[10] H. Masuda and K. Fukuda, "Ordered metal nanohole arrays made by a two-step replication of honeycomb structures of anodic alumina," Science, vol. 268, no. 5216, pp. 1466-1468, 1995.

[11] J. K. Lee, Y. Yi, H. J. Lee, S. Uhm, and J. Lee, "Electrocatalytic activity of Ni nanowires prepared by galvanic electrodeposition for hydrogen evolution reaction," Catalysis Today, vol. 146, no. 1-2, pp. 188-191, 2009.

[12] P.-C. Chen, Y.-M. Chang, P.-W. Wu, and Y.-F. Chiu, "Fabrication of Ni nanowires for hydrogen evolution reaction in a neutral electrolyte," International Journal of Hydrogen Energy, vol. 34, no. 16, pp. 6596-6602, 2009.

[13] C. S. Hsu, H. B. Lee, C. S. Lin, and C. Y. Lee, "Study on the electrodeposition of Ni-P nanowires and their electrocatalytic properties," Metallurgical and Materials Transactions A, vol. 41, no. 3, pp. 768-774, 2010.

[14] T. Iida, H. Matsushima, and Y. Fukunaka, "Water electrolysis under a magnetic field," Journal of the Electrochemical Society, vol. 154, no. 8, pp. E112-E115, 2007.

[15] H. Matsushima, D. Kiuchi, and Y. Fukunaka, "Measurement of dissolved hydrogen supersaturation during water electrolysis in a magnetic field," Electrochimica Acta, vol. 54, no. 24, pp. 58585862, 2009.

[16] M.-Y. Lin, L.-W. Hourng, and C.-W. Kuo, "The effect of magnetic force on hydrogen production efficiency in water electrolysis," International Journal of Hydrogen Energy, vol. 37, no. 2, pp. 13111320, 2012.

[17] C. Y. Yu, Y. L. Yu, H. Y. Sun et al., "Enhancement of the coercivity of electrodeposited nickel nanowire arrays," Materials Letters, vol. 61, no. 8-9, pp. 1859-1862, 2007.

[18] H. Chiriac, A.-E. Moga, M. Urse, I. Paduraru, and N. Lupu, "Preparation and magnetic properties of amorphous $\mathrm{NiP}$ and CoP nanowire arrays," Journal of Magnetism and Magnetic Materials, vol. 272-276, pp. 1678-1680, 2004.

[19] H. P. Klug and L. E. Alexander, X-Ray Diffraction Procedures, Wiley, New York, NY, USA, 2nd edition, 1974.

[20] H. Ezaki, M. Morinaga, S. Watanabe, and J. Saito, "Hydrogen overpotential for intermetallic compounds, TiAl, FeAl and NiAl, containing 3d transition metals," Electrochimica Acta, vol. 39, no. 11-12, pp. 1769-1773, 1994.

[21] I. Paseka, "Evolution of hydrogen and its sorption on remarkable active amorphous smooth $\mathrm{NiP}(\mathrm{x})$ electrodes," Electrochimica Acta, vol. 40, no. 11, pp. 1633-1640, 1995.

[22] T. Burchardt, V. Hansen, and T. Våland, "Microstructure and catalytic activity towards the hydrogen evolution reaction of electrodeposited NiPx alloys," Electrochimica Acta, vol. 46, no. 18, pp. 2761-2766, 2001.

[23] C. S. Hsu, H. B. Lee, C. S. Lin, and C. Y. Lee, “The electrocatalytic activity of electrodeposited Ni-P micro-patterned structure in acidic solution," Journal of Chinese Society of Mechanical Engineers, vol. 32, pp. 103-109, 2011. 

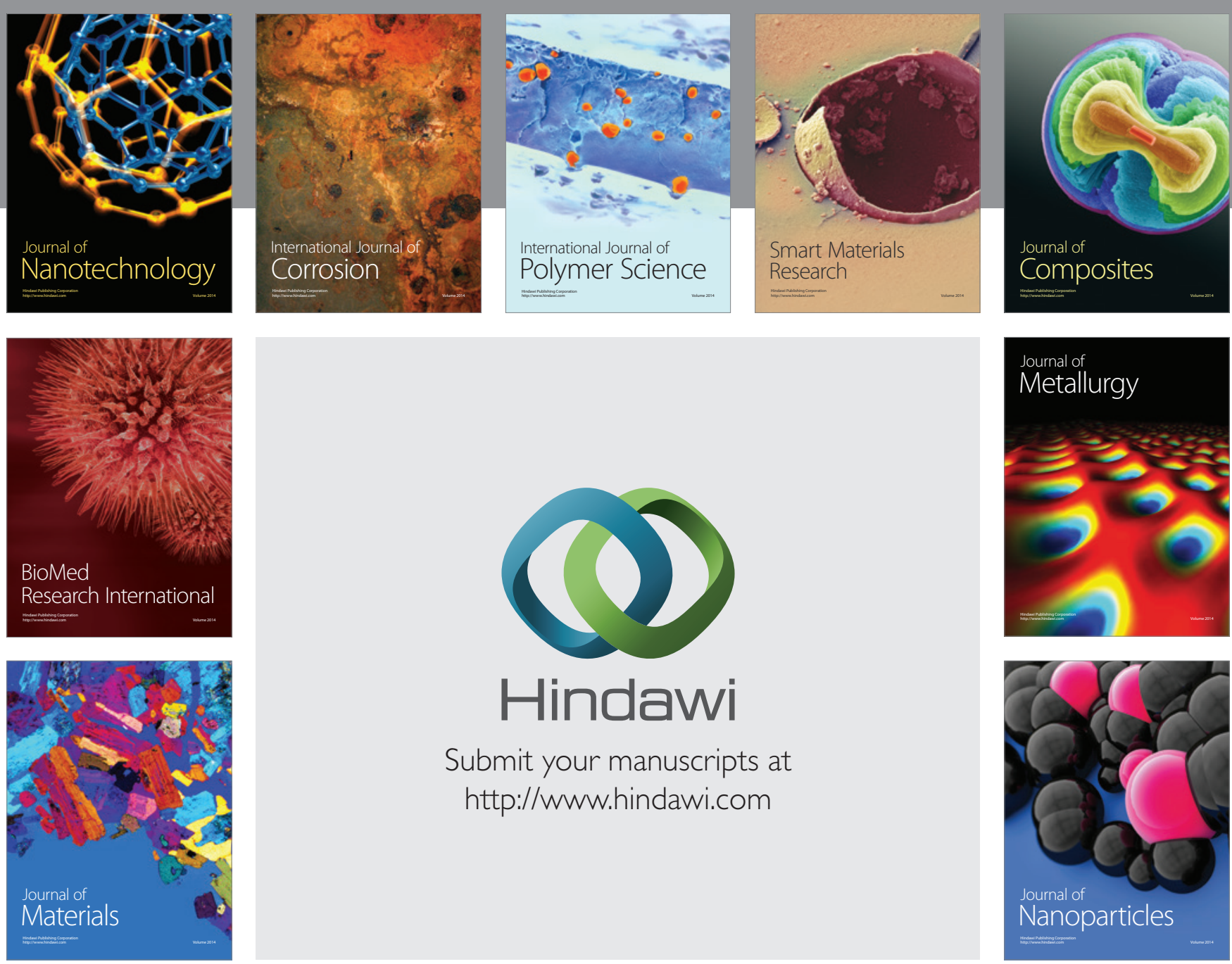

Submit your manuscripts at http://www.hindawi.com
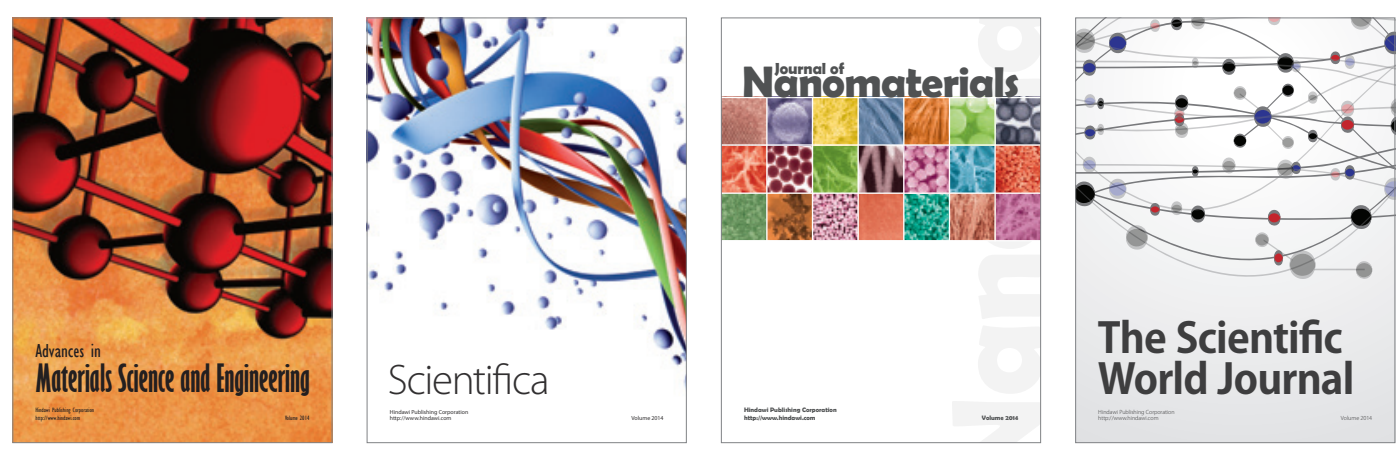

\section{The Scientific World Journal}
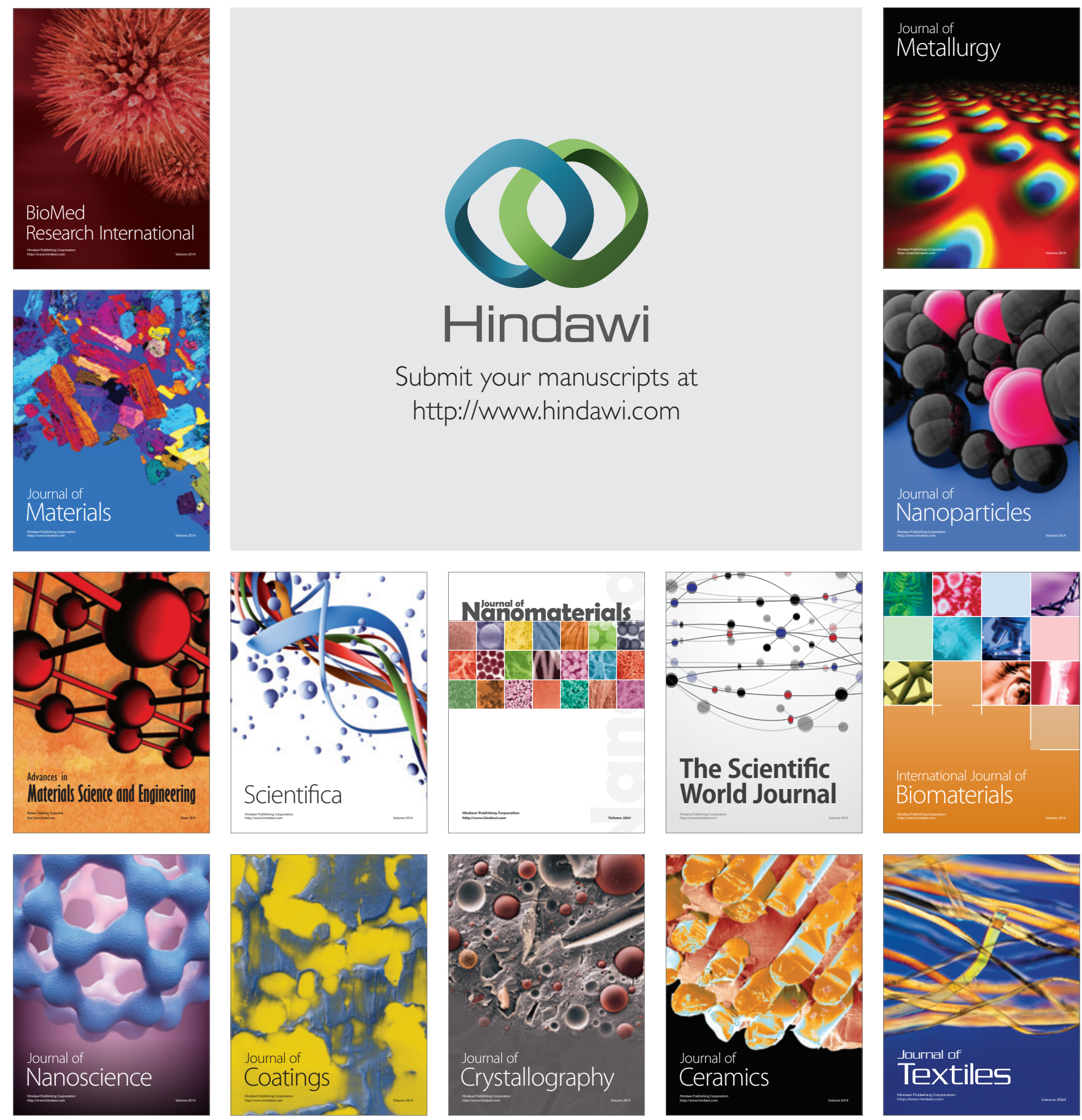